\title{
Tobramycin Inhalation Powder in Cystic Fibrosis Patients: Response by Age Group
}

\author{
David E Geller MD, Samya Z Nasr MD, Simon Piggott PhD, Ellie He PhD, \\ Gerhild Angyalosi MD, and Mark Higgins MD
}

\begin{abstract}
BACKGROUND: Tobramycin powder for inhalation (TIP) is a drug-device combination designed to reduce treatment time and improve ease of use compared with tobramycin inhalation solution (TIS) in cystic fibrosis (CF) patients. However, the ability of patients to use dry powder inhalers, and the efficacy of the treatments, may vary by age. METHODS: The "Establish a New Gold Standard for Efficacy and Safety With Tobramycin in Cystic Fibrosis" (EAGER) trial was a randomized, 24-week, multicenter, open-label, parallel-group study designed to evaluate the safety of TIP versus TIS in 553 subjects, ages $\geq 6$ years, with CF and $P$. aeruginosa infection. The main efficacy end point was percent-of-predicted $\mathrm{FEV}_{1}$ at week 20 (end of third cycle of treatment). A post hoc analysis was undertaken in 517 subjects who took $\geq 1$ dose of study medication, to evaluate the relative efficacy and safety of TIP and TIS by age group: $\geq 6$ to $<13$ y (children, $n=46$ ); $\geq 13$ to $<20 \mathrm{y}$ (adolescents, $n=114$ ); and $\geq 20 \mathrm{y}$ (adults, $n=357$ ). RESULTS: Improvements in percent-of-predicted $\mathrm{FEV}_{1}$ from baseline to end of cycle 3 were greatest in the children for both TIP and TIS. The treatment differences (TIP - TIS) were $4.7 \%$ (85\% CI -1.2 to 10.6$), 3.7 \%$ (85\% CI -0.1 to 7.5 ), and $-0.8 \%$ ( $85 \%$ CI -3.1 to 1.5 ) in children, adolescents, and adults, respectively. Sputum $P$. aeruginosa density decreased from baseline with both treatments, with comparable treatment differences across the age groups after 3 cycles: children -0.93 (85\% CI -2.4 to 0.5 ), adolescents -0.17 (85\% CI -1.2 to 0.8$)$, and adults -0.89 (85\% CI -1.3 to -0.4$)$. Overall, subject satisfaction scores were greater in all subjects with TIP, irrespective of age group. With the exception of cough and dysphonia, the safety profile of TIP was comparable to TIS, irrespective of age. CONCLUSIONS: TIP is comparable to TIS in efficacy outcomes and safety profile but had greater patient satisfaction in all the age groups. Key words: cystic fibrosis; topical anti-infective agents; tobramycin inhalation powder; Pseudomonas aeruginosa; age groups; drug delivery systems. [Respir Care 2014;59(3):388-398. (c) 2014 Daedalus Enterprises]
\end{abstract}

\section{Introduction}

Current treatment guidelines for cystic fibrosis $(\mathrm{CF})$ recommend that patients with Pseudomonas aeruginosa in-

Dr Geller is affiliated with the College of Medicine, Orlando Regional Campus, Florida State University, Orlando, Florida. Dr Nasr is affiliated with the Department of Pediatrics and Communicable Diseases, University of Michigan, Ann Arbor, Michigan. At the time of this study, Drs Piggott, Higgins, and He were affiliated Novartis Pharmaceuticals. Dr Angyalosi is affiliated with Novartis Pharmaceuticals, Basel, Switzerland.

This study was funded by Novartis Pharmaceuticals. Dr Geller has disclosed relationships with Gilead, Novartis Pharmaceuticals, and KaloBios. Dr Nasr has disclosed relationships with Gilead and Novartis Pharmaceuticals. fection receive inhaled anti-pseudomonal antibiotic therapy, either as an important part of early eradication strategies, ${ }^{1}$ or for long-term treatment of chronic $P$. aeruginosa infection, to preserve lung function and decrease the need for additional intravenous antibiotics. ${ }^{2}$ Until recently the only approved inhaled antibiotics for patients with CF were nebulized solutions of tobramycin or aztreonam, which can be time-consuming to administer: a factor that may be associated with poor adherence to therapy. ${ }^{3-5}$ In

Correspondence: David E Geller MD. E-mail: degeller2@earthlink.net.

DOI: $10.4187 /$ respcare.02264 
turn, poor adherence may have a detrimental impact on outcomes in CF.6,7

Nebulized tobramycin solution for inhalation (TIS) significantly improves lung function and reduces morbidity and mortality in patients with $\mathrm{CF}$ and $P$. aeruginosa infection. ${ }^{8-11}$ However, administration time is approximately 20 min per dose (twice per day), excluding the time required to clean and disinfect the nebulizer, ${ }^{12}$ which may adversely impact adherence. 5

Tobramycin inhalation powder (TIP) is a novel drugdevice combination designed to reduce the overall time of administration and treatment burden for CF patients, which improves adherence, compared to TIS. ${ }^{13}$ TIP delivers light, porous, engineered particles via the portable T-326 dry powder inhaler. ${ }^{14}$ The inhaler has low air flow resistance, which allows the patient to generate a high inspiratory flow and achieve reliable dose delivery. In studies in both healthy volunteers and patients with CF, TIP had a similar pharmacokinetic profile to TIS, but resulted in a more efficient and rapid delivery of tobramycin to the lungs. ${ }^{14-16}$ However, effective use of dry powder inhalers among patients with chronic respiratory diseases can be affected by factors such as age and disease severity. ${ }^{17,18}$ Therefore, it is important to confirm that the observed pharmacokinetic profile of TIP translates into favorable clinical outcomes, particularly in patients with lower inspiratory effort, such as young children and patients with more severe disease. Furthermore, there is evidence to suggest that the efficacy of CF treatments may vary according to age, regardless of the delivery route. ${ }^{10,19,20}$

The Establish a New Gold Standard for Efficacy and Safety With Tobramycin in Cystic Fibrosis (EAGER) trial, ${ }^{12}$ which evaluated the safety, efficacy, and convenience of TIP versus TIS for the treatment of $P$. aeruginosa infection in CF patients ( $\geq 6$ years) showed that TIP was comparable to TIS. The large EAGER trial cohort provided an opportunity to investigate the efficacy and safety profile of TIP in different age groups. Therefore, we undertook a post hoc subgroup analysis of EAGER data to assess the effect of TIP and TIS on the main efficacy end point, lung function, and other secondary efficacy end points, including microbiology and treatment satisfaction, and to compare their safety profiles in children, adolescents, and adults.

\section{Methods}

This study was conducted at Novartis Pharmaceuticals Horsham Research Centre, Horsham, West Sussex, United Kingdom. EAGER was a 24-week international, multicenter, open-label, active-controlled, randomized, parallelgroup study (http://clinicaltrials.gov NCT00388505) designed to evaluate the safety of TIP compared to TIS, conducted between February 2006 and March 2009. It was approved

\section{QUICK LOOK}

\section{Current knowledge}

Tobramycin solution for inhalation significantly improves lung function and reduces morbidity and mortality in patients with cystic fibrosis and Pseudomonas infection. Tobramycin inhalation powder is a drug/device combination designed to reduce treatment time.

\section{What this paper contributes to our knowledge}

Tobramycin powder was comparable to tobramycin solution in efficacy and safety, and had higher patientsatisfaction ratings across a range of patient ages.

by the ethics committee or institutional review board at each study center, and conducted in accordance with the Declaration of Helsinki and Good Clinical Practice.

\section{Subjects}

Patients with $\mathrm{CF}$, age $\geq 6$ years, percent-of-predicted $\mathrm{FEV}_{1}$ of $25-75 \%,{ }^{21}$ and sputum or throat-swab cultures positive for $P$. aeruginosa within 6 months of screening (and confirmed at enrollment) were eligible.

\section{Study Design}

The methods of the EAGER trial are described elsewhere. ${ }^{12}$ The study comprised 3 treatment cycles, and each cycle had 28 days on treatment, followed by 28 days off treatment. The total duration of the study was 24 weeks. Subjects were randomized 3:2 to receive either TIP (4 capsules/112 mg tobramycin) twice daily via the T-326 inhaler or TIS (300 mg/5 mL; TOBI) twice daily via the Pari LC Plus jet nebulizer and DeVilbiss PulmoAide compressor, or suitable alternative.

\section{Study Assessments}

The main efficacy measurement was relative change in percent-of-predicted $\mathrm{FEV}_{1}$ from baseline (pre-dose, day 1) to end of dosing in cycle 3. Other efficacy measures included change in sputum $P$. aeruginosa density $\left(\log _{10}\right.$ colony-forming units/g sputum), any other anti-pseudomonal antibiotic use (including any new antibiotics started during the study period), and hospitalizations for respiratory events. Patient-reported satisfaction with treatment was assessed with the validated Treatment Satisfaction Questionnaire for Medication, ${ }^{22}$ modified with the addition of 4 questions relating to ease of use and convenience. The 


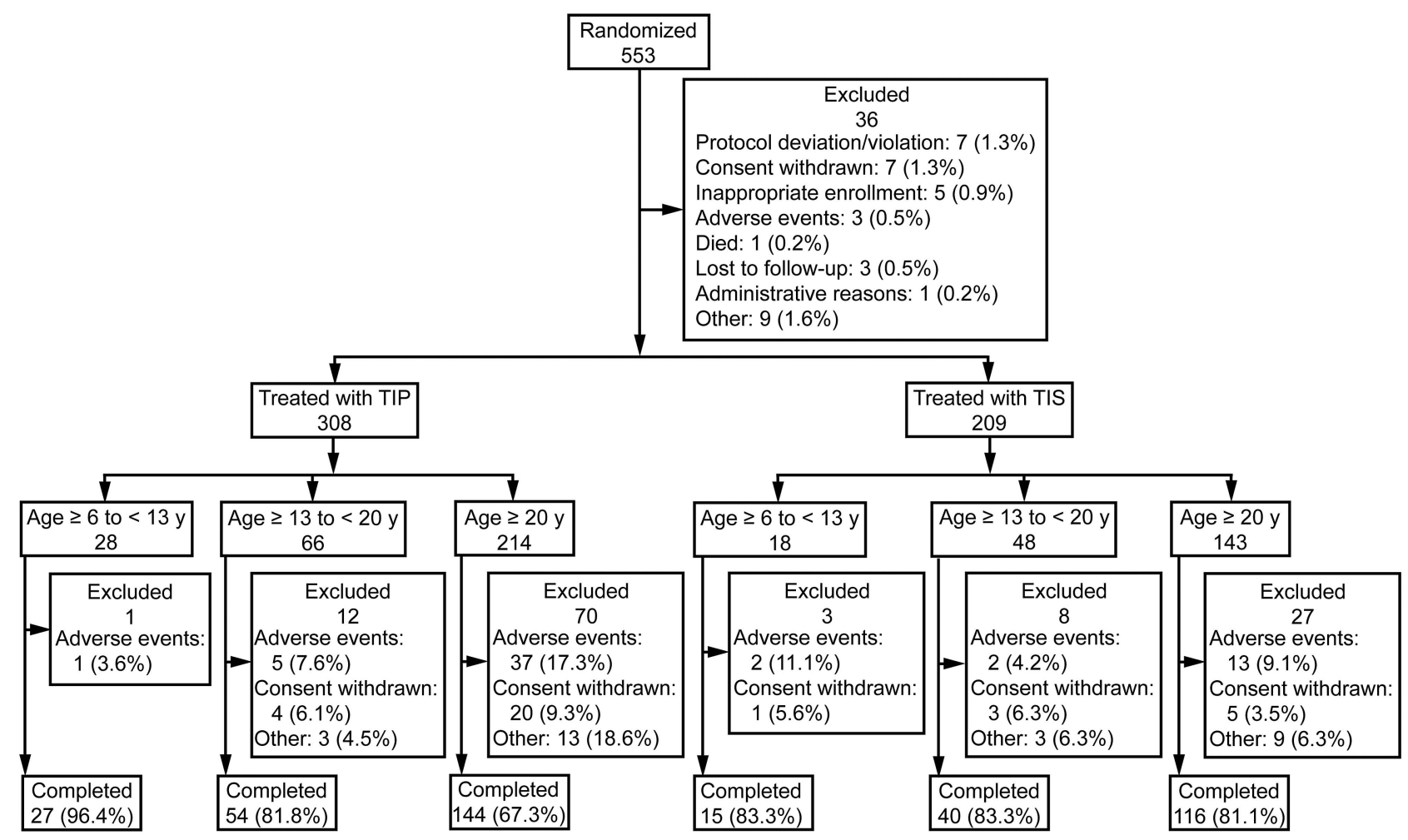

Fig. 1. Patient disposition diagram.

safety assessments included documented reporting of all adverse events.

\section{Evaluation and Statistical Analyses}

For this subgroup analysis the subjects were segmented into 3 age groups: $\geq 6$ to $<13$ years (children), $\geq 13$ to $<20$ years (adolescents), and $\geq 20$ years (adults).

The original sample size was based on the primary end point, safety. For efficacy, the inclusion of 500 subjects (300 TIP, 200 TIS) provided 96\% power to demonstrate non-inferiority of TIP to TIS with regard to relative change from baseline in percent-of-predicted $\mathrm{FEV}_{1}$ after 3 cycles, based on a non-inferiority margin of $6 \%$ and a one-sided significance level of .15 (assuming a $1 \%$ true TIS-TIP treatment difference, and a $20 \%$ standard deviation). This efficacy end point (treatment difference in percent-of-predicted $\mathrm{FEV}_{1}$ ) was estimated using an analysis of covariance that included treatment, baseline percent-of-predicted $\mathrm{FEV}_{1}$, chronic macrolide use, subgroup, and subgroup-bytreatment interaction in the model. Non-inferiority between treatment groups was demonstrated if the lower bound of the $85 \%$ CIs were higher than the lower defined margin (ie, $\geq 6 \%$ ). To retain consistency with the original study, summary statistics and $85 \%$ CIs for treatment differences in percent-of-predicted $\mathrm{FEV}_{1}$, sputum $P$. aeruginosa density, and Treatment Satisfaction Questionnaire for Medi- cation score were calculated for analyses by subgroup. The effect of age group on the primary end point was estimated using a generalized linear model with relative change in percent-of-predicted $\mathrm{FEV}_{1}$ as the dependent variable.

All other end points in this post hoc analysis are presented as descriptive statistics only.

\section{Results}

In the original EAGER study, 517 out of 553 randomized patients received at least one dose of study medication (TIP $n=308$, TIS $n=209$ ) and were included in the efficacy and safety populations. There were 46 children, 114 adolescents, and 357 adults (Fig. 1).

Baseline demographic and clinical characteristics (Table 1) were similar in both treatment groups as a whole, although there was a higher proportion of females in the children treated with TIP than in the children treated with TIS $(60.7 \%$ vs $44.4 \%)$. Prior TIS use (defined as 'everused') and baseline disease severity were also lower in the children treated with TIP. Baseline mean percent-of-predicted $\mathrm{FEV}_{1}$ was relatively comparable between the adolescent and adult groups, although the children who received TIP had a higher baseline percent-of-predicted $\mathrm{FEV}_{1}$ than those who received TIS (mean percent-of-predicted $\mathrm{FEV}_{1} 60.0 \%$ vs $50.4 \%$ ). 
Table 1. Baseline Demographic and Clinical Characteristics

\begin{tabular}{|c|c|c|c|c|c|c|}
\hline & \multicolumn{2}{|c|}{ Age $\geq 6$ to $<13$ y $(n=46)$} & \multicolumn{2}{|c|}{ Age $\geq 13$ to $<20$ y $(n=114)$} & \multicolumn{2}{|c|}{ Age $\geq 20$ y $(n=357)$} \\
\hline & $\operatorname{TIP}(n=28)$ & TIS $(n=18)$ & $\operatorname{TIP}(n=66)$ & TIS $(n=48)$ & TIP $(n=214)$ & TIS $(n=143)$ \\
\hline Male, no. (\%) & $11(39.3)$ & $10(55.6)$ & $34(51.5)$ & $26(54.2)$ & $126(58.9)$ & $79(55.2)$ \\
\hline Female, no. $(\%)$ & $17(60.7)$ & $8(44.4)$ & $32(48.5)$ & $22(45.8)$ & $88(41.1)$ & $64(44.8)$ \\
\hline$\%$ predicted $\mathrm{FEV}_{1}$ mean $\pm \mathrm{SD}$ & $60 \pm 16.4$ & $50.4 \pm 14.4$ & $57.3 \pm 12.6$ & $55.9 \pm 17.12$ & $50.7 \pm 13.8$ & $52.0 \pm 15.7$ \\
\hline$\%$ perdicted $\mathrm{FEV}_{1}<50 \%$, no. $(\%)$ & $7(25.0)$ & $9(50.0)$ & $18(27.3)$ & $16(33.3)$ & $97(45.3)$ & $70(49.0)$ \\
\hline$\%$ predicted $\mathrm{FEV}_{1} \geq 50 \%$, no. $(\%)$ & $21(75.0)$ & $9(50.0)$ & $48(72.7)$ & $32(66.6)$ & $117(54.7)$ & $73(51.0)$ \\
\hline $\begin{array}{l}\text { Pseudomonas aeruginosa sputum density, } \\
\text { mean } \pm \mathrm{SD} \log _{10} \text { colony-forming units }\end{array}$ & $7.67 \pm 0.89$ & $7.31 \pm 1.75$ & $7.30 \pm 1.64$ & $7.16 \pm 1.73$ & $7.16 \pm 1.50$ & $7.42 \pm 1.46$ \\
\hline Previously used tobramycin, no. (\%) & $21(75.0)$ & $16(88.9)$ & $56(84.9)$ & $43(89.6)$ & $176(82.2)$ & $113(79.0)$ \\
\hline $\begin{array}{l}\text { Previously used anti-pseudomonal antibiotics, } \\
\text { no. }(\%)\end{array}$ & $28(100.0)$ & $18(100.0)$ & $65(98.5)$ & $45(93.8)$ & $200(93.5)$ & $128(89.5)$ \\
\hline $\begin{array}{l}\text { TIP }=\text { tobramycin inhalation powder } \\
\text { TIS }=\text { tobramycin inhalation solution }\end{array}$ & & & & & & \\
\hline
\end{tabular}

Table 2. Change in $\mathrm{FEV}_{1}$ by Age Group, Treatment Cycle, and Baseline percent-of-predicted FEV

\begin{tabular}{|c|c|c|c|c|c|c|c|c|c|c|c|c|}
\hline & \multicolumn{12}{|c|}{ Mean \pm SD Relative Change in $\mathrm{FEV}_{1} \%$} \\
\hline & \multicolumn{4}{|c|}{ Age $\geq 6$ to $<13$ y $(n=46)$} & \multicolumn{4}{|c|}{ Age $\geq 13$ to $<20$ y $(n=114)$} & \multicolumn{4}{|c|}{ Age $\geq 20$ y $(n=357)$} \\
\hline & $\begin{array}{c}\text { TIP } \\
(n=28)\end{array}$ & $\begin{array}{c}\text { TIS } \\
(n=18)\end{array}$ & $\begin{array}{c}\text { Difference } \\
\text { TIP-TIS } \\
\text { Mean }(85 \% \text { CI) }\end{array}$ & $P$ & $\begin{array}{c}\text { TIP } \\
(n=66)\end{array}$ & $\begin{array}{c}\text { TIS } \\
(n=48)\end{array}$ & $\begin{array}{c}\text { Difference } \\
\text { TIP-TIS } \\
\text { Mean }(85 \% \text { CI) }\end{array}$ & $P$ & $\begin{array}{c}\text { TIP } \\
(n=214)\end{array}$ & $\begin{array}{c}\text { TIS } \\
(n=143)\end{array}$ & $\begin{array}{c}\text { Difference } \\
\text { TIP-TIS } \\
\text { Mean }(85 \% \text { CI) }\end{array}$ & $P$ \\
\hline $\begin{array}{l}\% \text { predicted } \mathrm{FEV}_{1}<50 \% \text {, } \\
\text { no. }(\%)\end{array}$ & 7 & 9 & & & 18 & 16 & & & 97 & 70 & & \\
\hline $\begin{array}{l}\% \text { predicted } \mathrm{FEV}_{1} \geq 50 \% \text {, } \\
\text { no. }(\%)\end{array}$ & 21 & 9 & & & 48 & 32 & & & 117 & 73 & & \\
\hline \multicolumn{13}{|l|}{ Cycle 1 (week 4) } \\
\hline All patients & $6.3 \pm 29.9$ & $12.7 \pm 22.9$ & $-6.4(-19$ to 6.0$)$ & .46 & $8.3 \pm 17.76$ & $4.8 \pm 9.6$ & $3.5(-0.8$ to 7.9$)$ & .24 & $0.5 \pm 17.9$ & $2.0 \pm 13.9$ & $-1.5(-4.2$ to 1.2$)$ & .42 \\
\hline$\%$ predicted $\mathrm{FEV}_{1}<50 \%$ & $41.8 \pm 34.0$ & $21.8 \pm 24.9$ & $20.0(-2.4$ to 42.4$)$ & .201 & $17.6 \pm 27.5$ & $10.1 \pm 11.8$ & $7.5(-5.2$ to 20.3$)$ & .39 & $4.2 \pm 21.3$ & $3.7 \pm 14.9$ & $0.5(-4.0$ to 5.0$)$ & .87 \\
\hline$\%$ predicted $\mathrm{FEV}_{1} \geq 50 \%$ & $-5.5 \pm 16.5$ & $2.3 \pm 15.9$ & $-7.8(-17.9$ to 2.2$)$ & .26 & $5.4 \pm 12.4$ & $2.8 \pm 7.9$ & $2.6(-1.1$ to 6.3$)$ & .31 & $-2.4 \pm 14.1$ & $0.3 \pm 12.7$ & $-2.7(-5.8$ to 0.4$)$ & .21 \\
\hline \multicolumn{13}{|c|}{ Cycle 3 (week 20) } \\
\hline All patients & $10.4 \pm 25.9$ & $9.4 \pm 18.9$ & $1.0(-10.2$ to 12.1$)$ & .09 & $6.8 \pm 18.5$ & $3.9 \pm 19.4$ & $2.9(-2.8$ to 8.6$)$ & .47 & $0.3 \pm 18.7$ & $0.9 \pm 16.6$ & $-0.6(-3.8$ to 2.6$)$ & .79 \\
\hline$\%$ predicted $\mathrm{FEV}_{1}<50 \%$ & $38.0 \pm 32.5$ & $15.6 \pm 15.6$ & $22.4(1.5$ to 43.4$)$ & .131 & $18.5 \pm 23.3$ & $10.3 \pm 28.1$ & $8.2(-6.9$ to 23.2$)$ & .43 & $4.7 \pm 22.5$ & $3.9 \pm 17.8$ & $0.8(-4.8$ to 6.3$)$ & .84 \\
\hline$\%$ predicted $\mathrm{FEV}_{1} \geq 50 \%$ & $1.1 \pm 15.3$ & $4.0 \pm 20.9$ & $-2.9(-13.2$ to 7.6$)$ & .69 & $3.2 \pm 15.3$ & $0.8 \pm 13.0$ & $2.4(-2.9$ to 7.5$)$ & .52 & $-2.6 \pm 15.1$ & $-2.0 \pm 15.0$ & $-0.6(-4.3$ to 3.0$)$ & .81 \\
\hline $\mathrm{IP}=$ tobramycin inhalation $\mathrm{po}$ & & & & & & & & & & & & \\
\hline
\end{tabular}

Adherence to study medication was generally good ( $\geq 90 \%$ of doses taken overall) and comparable between the age groups. The highest adherence was in the children (average of $96.5-98.7 \%$ doses taken overall, vs $89.6-93.7 \%$ in the adults). The overall discontinuation rates for TIP were $3.6 \%$ in the children, $18.2 \%$ in the adolescents, and $32.7 \%$ in the adults, while the discontinuation rates with TIS were $16.7 \%$ in the children and adolescents, and $18.9 \%$ in the adults.

\section{Efficacy}

Spirometry. Improvements in unadjusted percent-ofpredicted $\mathrm{FEV}_{1}$ relative change from baseline to the end of dosing in cycle 3 were observed for both TIP and TIS across all age groups (Table 2). The least-mean-squares differences between the treatment groups (TIP-TIS, controlling for baseline severity) decreased with age: $4.7 \%$ (85\% CI -1.2 to 10.6$)$ in the children, $3.7 \%(-0.1$ to 7.5$)$ in the adolescents, and $-0.8 \%(-3.1$ to 1.5$)$ in the adults (Fig. 2). Interaction testing found age group a significant factor for predicting relative change from baseline in percent-of-predicted $\mathrm{FEV}_{1}$ for both TIP and TIS $(P<.001)$. However, there was insufficient power to distinguish between different treatment effects of TIP and TIS within each age group.

In all the treatment cycles, and across all the age groups the improvements in subjects with more severe disease 


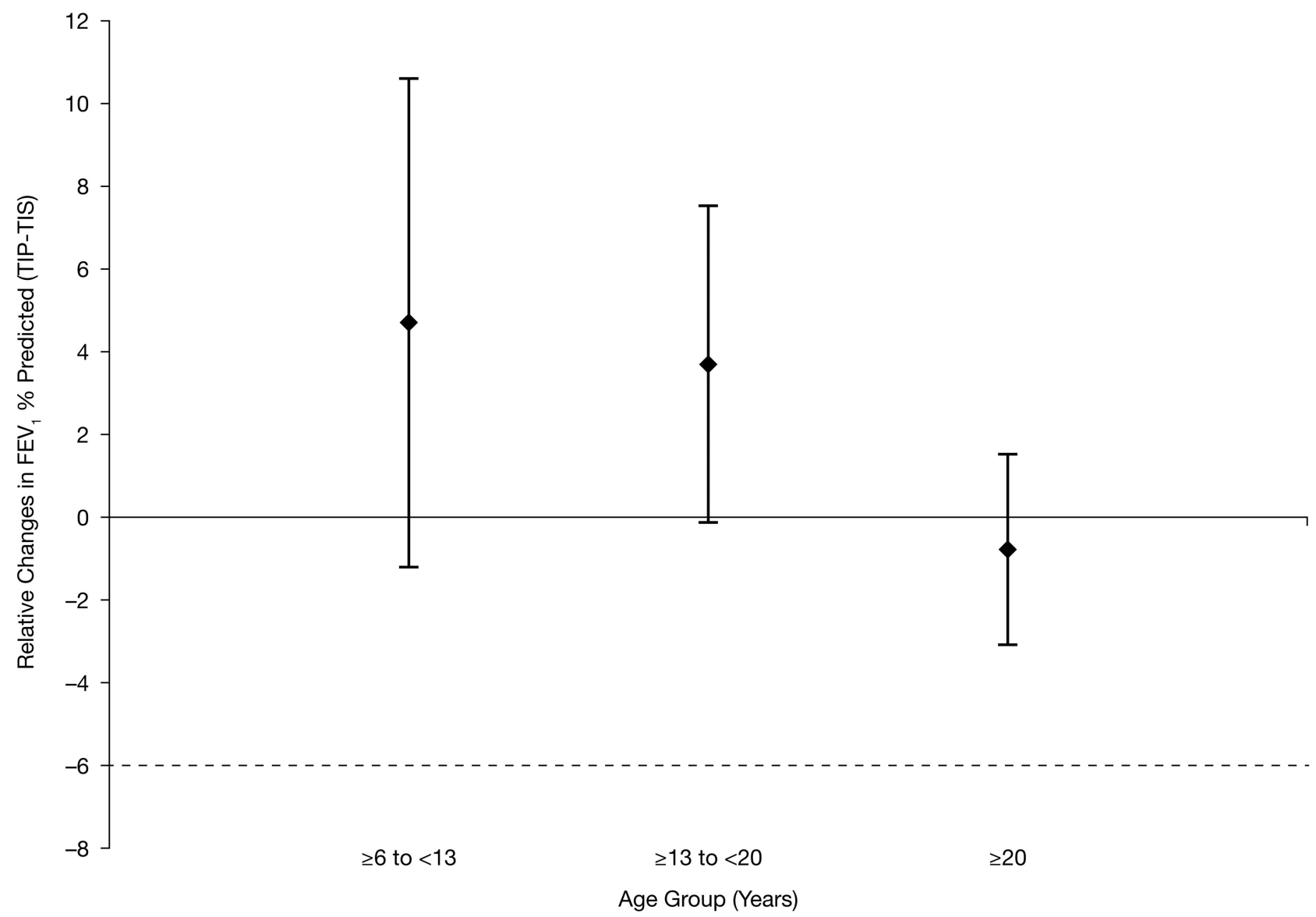

Fig. 2. Change in percent-of-predicted $\mathrm{FEV}_{1}$ from baseline to end of dosing in cycle 3 . The values are least-mean-square differences between the tobramycin powder for inhalation (TIP) and tobramycin inhalation solution (TIS) treatment groups. The whisker bars represent $85 \%$ one-sided confidence intervals. The dotted line represents the boundary for non-inferiority.

(percent-of-predicted $\mathrm{FEV}_{1}<50 \%$ ) were greater than in those with less severe disease, in both the TIP and TIS treatment groups (see Table 2).

Microbiology. P. aeruginosa sputum density decreased from baseline in both treatment groups at all measured time points, irrespective of age, with no differences between TIP and TIS overall, except in the adults at the end of cycle 1 and cycle 3 , and in the adolescents at week 16 $(P \leq .02$ in favor of TIP) (Table 3$)$.

The magnitude of mean change from baseline was greater in the TIP treatment group, and the greatest reduction was in the children (Fig. 3A). Furthermore, in the children the magnitude of the reduction in $P$. aeruginosa sputum density at the end of each dosing period increased with successive treatment cycles and was greatest on day 28 of cycle 3, particularly in the TIP treatment group (see Fig. 3B and Table 3). In the adolescents and adults the magnitude of the reduction in $P$. aeruginosa sputum density at the end of each dosing period decreased with successive cycles and was greatest after cycle 1 (see Fig. 3B).

\section{Anti-pseudomonal Antibiotic Use (Any Route) and Hospitalizations}

Fewer children in the TIP group than the TIS group were treated with concomitant anti-pseudomonal antibiotics $(50.0 \%$ vs $83.3 \%$, compared with $65.6 \%$ vs $55.0 \%$ for the total population) (Fig. 4). Mean antibiotic treatment duration over the 3 cycles was longer for children treated with TIP than those treated with TIS (52.6 d vs $38.2 \mathrm{~d}$ ) when considering only those who received antipseudomonal antibiotics. Over the entire 6 to $<13$ year age group (including children who did not receive antibiotics), mean antibiotic treatment duration was shorter for all TIP-treated versus TIS-treated children ( $26.3 \mathrm{~d}$ vs $31.8 \mathrm{~d}$ per subject). In the adult group both of these trends were reversed. The most commonly prescribed antipseudomonals were oral antibiotics (quinolones). Percentages of subjects receiving new intravenous antipseudomonal antibiotics were closely matched across all ages and treatment arms: for TIP and TIS, respectively, 


\section{Tobramycin Inhalation Powder in Cystic Fibrosis Patients: Response by Age Group}

Table 3. Change in Pseudomonas aeruginosa Sputum Density From Baseline at the End of Each Dosing Cycle

\begin{tabular}{|c|c|c|c|c|c|c|c|c|c|c|c|c|}
\hline & \multicolumn{12}{|c|}{ Baseline or Change in Pseudomonas aeruginosa Sputum Density, mean \pm SD $\log _{10}$ Colony-Forming Units, for Sum of All Biotypes } \\
\hline & \multicolumn{4}{|c|}{ Age $\geq 6$ to $<13$ y $(n=46)$} & \multicolumn{4}{|c|}{ Age $\geq 13$ to $<20$ y $(n=114)$} & \multicolumn{4}{|c|}{ Age $\geq 20$ y $(n=357)$} \\
\hline & $\begin{array}{c}\mathrm{TIP} \\
(n=28)\end{array}$ & $\begin{array}{c}\text { TIS } \\
(n=18)\end{array}$ & $\begin{array}{c}\text { Difference } \\
\text { TIP-TIS } \\
\text { Mean }(85 \% \text { CI) }\end{array}$ & $P$ & $\begin{array}{c}\mathrm{TIP} \\
(n=66)\end{array}$ & $\begin{array}{c}\text { TIS } \\
(n=48)\end{array}$ & $\begin{array}{c}\text { Difference } \\
\text { TIP-TIS } \\
\text { Mean }(85 \% \text { CI) }\end{array}$ & $P$ & $\begin{array}{c}\left.\operatorname{TIP}_{(n}^{=} 214\right) \\
\text {. }\end{array}$ & $\begin{array}{c}\text { TIS } \\
(n=143)\end{array}$ & $\begin{array}{c}\text { Difference } \\
\text { TIP-TIS } \\
\text { Mean }(85 \% \text { CI) }\end{array}$ & $P$ \\
\hline \multicolumn{13}{|l|}{ Cycle 1} \\
\hline $\begin{array}{l}\text { Baseline, } \\
\text { raw value }\end{array}$ & $7.67 \pm 0.89$ & $7.31 \pm 1.75$ & 0.36 (NA) & $\mathrm{NA}$ & $7.30 \pm 1.64$ & $7.16 \pm 1.73$ & 0.14 (NA) & NA & $7.16 \pm 1.50$ & $7.42 \pm 1.46$ & -0.26 (NA) & NA \\
\hline Week 4 & $-1.43 \pm 1.46$ & $-0.95 \pm 1.67$ & $-0.48(-1.4$ to 0.5$)$ & .46 & $-1.76 \pm 1.81$ & $-1.96 \pm 2.22$ & $0.2(-0.5$ to 0.9$)$ & .68 & $-1.79 \pm 2.04$ & $-1.18 \pm 2.00$ & $-0.61(-0.1$ to -0.2$)$ & .02 \\
\hline \multicolumn{13}{|c|}{ ( } \\
\hline Week 16 & $-1.26 \pm 2.48$ & $-0.41 \pm 1.02$ & $-0.85(-2.1$ to 0.4$)$ & .32 & $-0.62 \pm 1.71$ & $0.32 \pm 1.20$ & $-0.94(-1.5$ to -0.4$)$ & .02 & $-0.20 \pm 1.72$ & $-0.10 \pm 1.57$ & -0.1 ( -0.4 to 0.2$)$ & .66 \\
\hline Week 20 & $-2.54 \pm 2.01$ & $-1.23 \pm 1.08$ & $-1.31(-2.3$ to -0.3$)$ & .07 & $-1.21 \pm 2.03$ & $-0.69 \pm 1.96$ & $-0.52(-1.3$ to 0.3$)$ & .36 & $-1.63 \pm 2.02$ & $-0.73 \pm 1.81$ & $-0.9(-1.3$ to -0.5$)$ & .001 \\
\hline $\begin{aligned} \text { TIP } & =\text { tobram } \\
\text { TIS } & =\text { tobram } \\
\text { NA } & =\text { not ap }\end{aligned}$ & $\begin{array}{l}\text { in inhalation po } \\
\text { in inhalation so } \\
\text { able }\end{array}$ & $\begin{array}{l}\text { wder } \\
\text { lution }\end{array}$ & & & & & & & & & & \\
\hline
\end{tabular}

$32 \%$ vs $39 \%$ in children, $32 \%$ vs $31 \%$ in adolescents, and $36 \%$ vs $33 \%$ in adults.

The rate of hospitalizations due to respiratory events tended to be higher in the TIS-treated children and similar between the other treatment age groups (Fig. 5). Mean duration of hospitalization in those who were hospitalized was similar between the TIP and TIS-treated subjects in the youngest and oldest age groups: children 17.8 days versus 16.4 days; adults 17.2 days versus 14 days. In hospitalized adolescents the mean duration of hospitalization was shorter in the TIP group (10.4 d) than in the TIS group (17.2 d). When all subjects were analyzed, including those not requiring hospitalization, overall mean duration of hospitalizations was lower in the TIP-treated than the TIStreated subjects across all age groups.

\section{Patient-Reported Treatment Satisfaction}

Scores for convenience were higher in subjects receiving TIP, compared with TIS, across all age groups $(P \leq .005)$. Adolescent and adult subjects were more satisfied with the effectiveness of treatment with TIP than with TIS $(P<.001)$. Global satisfaction scores were also higher in the oldest subjects receiving TIP, compared with those receiving TIS (least-mean-square satisfaction score 75.1 and 69.6 respectively, $P<.01$ ). There were no differences between treatments in subjects' perceptions of side effects in any of the age groups (Table 4).

\section{Safety}

The frequency and pattern of adverse events reported were broadly similar between both treatments and across all age groups (Table 5). However, cough and dysphonia were reported more frequently in the TIP-treated than the TIS-treated subjects, across all age groups. Conversely, upper respiratory tract infections were 3 times more fre- quent in subjects receiving TIS than in those receiving TIP in children and adolescents: $22.2 \%$ versus $7.1 \%$, and $12.5 \%$ versus $4.5 \%$, respectively.

Fewer children on TIP discontinued study medication as a result of adverse events, compared with those on TIS (3.6\% vs $11.1 \%$, respectively), but the opposite was true for the adult subjects (18.2\% on TIP discontinued vs $9.1 \%$ on TIS).

\section{Discussion}

This post hoc analysis of the EAGER study shows that the efficacy of TIP, as measured by improvement in percent-of-predicted $\mathrm{FEV}_{1}$ and reduction in $P$. aeruginosa sputum density, is maintained across different age groups. Also, the efficacy of TIP was similar to that of TIS across the age groups. While some treatment differences were seen for reduction in $P$. aeruginosa sputum densities in the 2 older subject groups, the clinical relevance of this is unknown. Overall the results are consistent with the whole population data from the original study, showing non-inferiority of TIP to TIS. ${ }^{12}$

Interestingly, the largest numerical improvement in percent-of-predicted $\mathrm{FEV}_{1}$ was with TIP in children ages 6-12 years with the lowest baseline lung function (percent-of-predicted $\mathrm{FEV}_{1}<50 \%$ ). This may be counterintuitive since the youngest, sickest children should have the most difficulty generating the required flow and volume necessary to ensure the aerosol reaches the lower airways. Tiddens et $\mathrm{al}^{23}$ investigated this concept in a study in which inspiratory profiles of CF subjects of varying ages and disease severities were recorded using several resistors to simulate the representative resistance of a dry powder inhaler. By reproducing the inspiratory profiles representative of the T-326 inhaler in vitro with a breath simulator, researchers demonstrated that even a low inspired flow of $30 \mathrm{~L} / \mathrm{min}$ and volume of $0.6 \mathrm{~L}$ could empty 


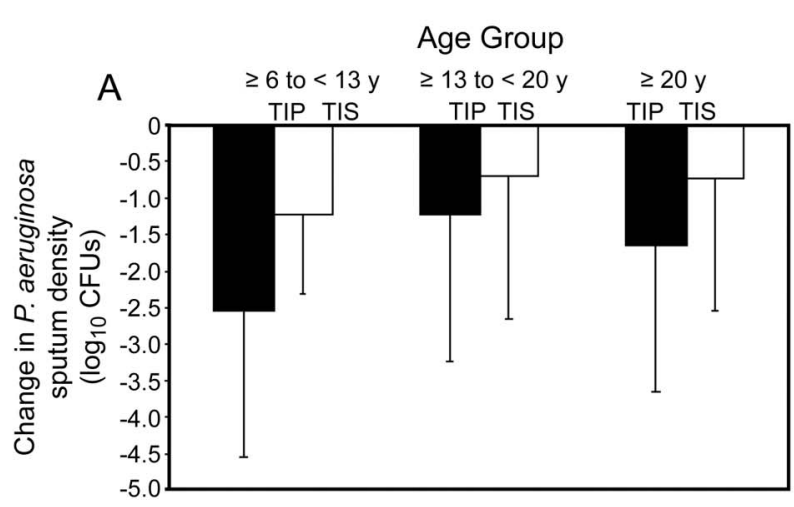

B
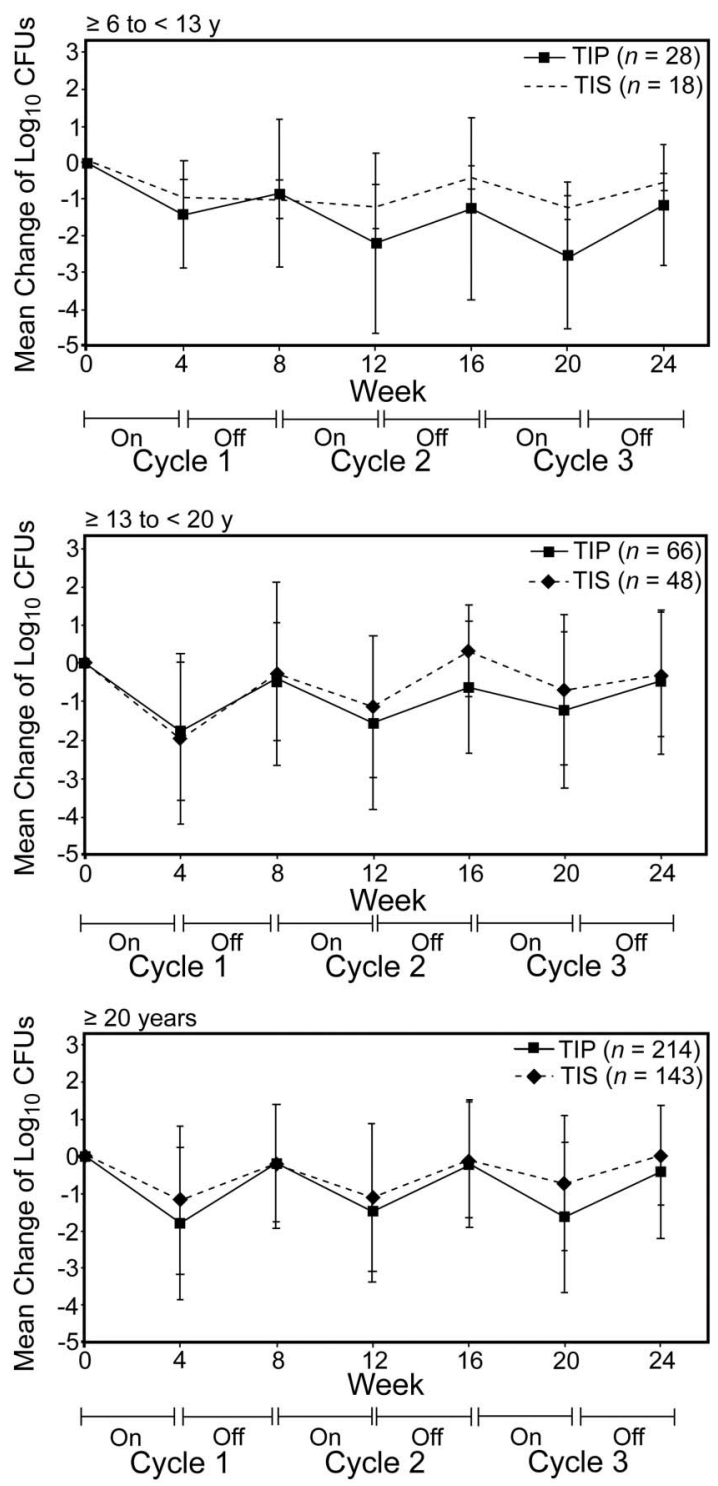

Fig. 3. Mean \pm SD change in sputum Pseudomonas aeruginosa (combined data for all biotypes: dry, mucoid, and small-colony variant) density from baseline to end of treatment in (A) entire cohort and (B) the 3 age subgroups. CFU = colony-forming unit. TIP = tobramycin inhalation powder. TIS = tobramycin inhalation solution.

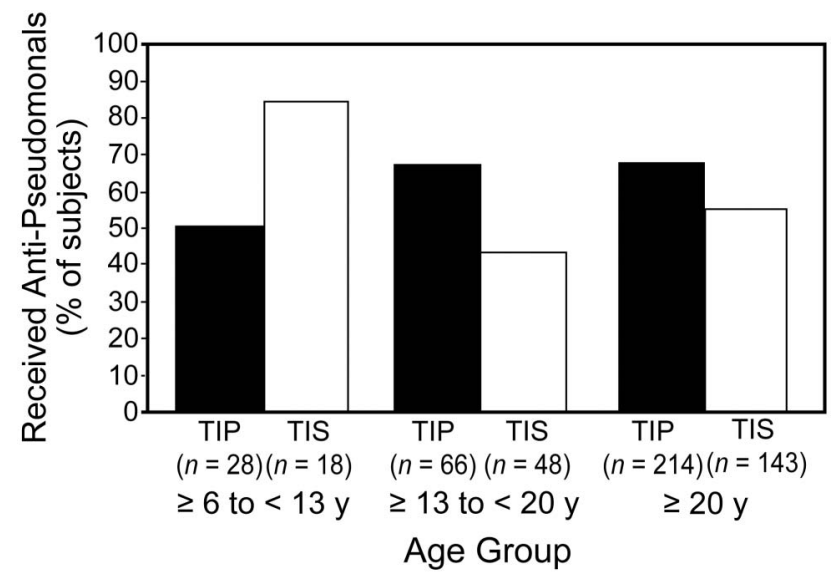

Fig. 4. Concomitant anti-pseudomonal antibiotic use. The values are the percentages of subjects who received tobramycin inhalation powder (TIP) or tobramycin inhalation solution (TIS) in whom any anti-pseudomonal antibiotic use was recorded

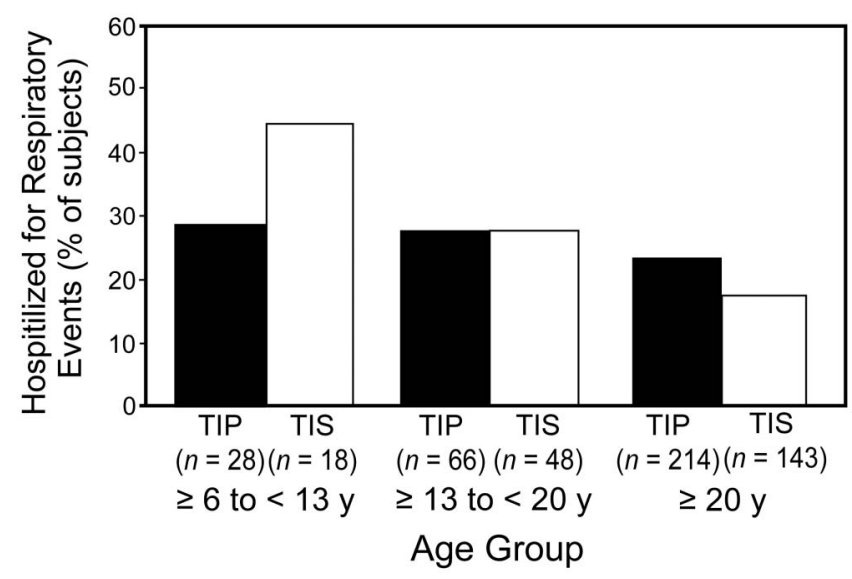

Fig. 5. Hospitalizations due to respiratory events. The values are the percentages of subjects who received tobramycin inhalation powder (TIP) or tobramycin inhalation solution (TIS) and were hospitalized for respiratory events

a TIP capsule in 2 efforts, likely due to the improved flow characteristics of the light, porous particles ${ }^{14}$ and to the low-to-medium resistance of the T-326 inhaler. This suggests that even the young and sick children with $\mathrm{CF}$ who have difficulty in achieving the required inspiratory profile for adequate dosing of inhaled antibiotics via conventional nebulizer systems can deliver the required dose of tobramycin to the lower airways using the TIP system. The treatment differences in relative change in percent-of-predicted $\mathrm{FEV}_{1}$ (TIP-TIS) of $4.7,3.7$, and $-0.8 \%$ for children, adolescents, and adults, respectively, indicate that younger children, including those with more severe disease, are able to use the T-326 inhaler device as effectively as TIS.

Some interesting trends were detected in the different age groups in terms of antibiotic use and hospitalizations, although event rates were too low to allow statistical com- 


\section{Tobramycin Inhalation Powder in Cystic Fibrosis Patients: Response by Age Group}

Table 4. Patient-Reported Satisfaction With Treatment, as Assessed With the Treatment Satisfaction Questionnaire for Medication

\begin{tabular}{|c|c|c|c|c|c|c|c|c|c|c|c|c|}
\hline & \multicolumn{12}{|c|}{ Patient Satisfaction Score } \\
\hline & \multicolumn{4}{|c|}{$\geq 6$ to $<13$ y $(n=46)$} & \multicolumn{4}{|c|}{$\geq 13$ to $<20$ y $(n=114)$} & \multicolumn{4}{|c|}{$\geq 20$ y $(n=357)$} \\
\hline & $\begin{array}{c}\text { TIP } \\
(n=28)\end{array}$ & $\begin{array}{c}\text { TIS } \\
(n=18)\end{array}$ & $\begin{array}{c}\text { Difference } \\
\text { TIP-TIS } \\
\text { LMS* }(85 \% \text { CI) }\end{array}$ & $P$ & $\begin{array}{c}\text { TIP } \\
(n=66)\end{array}$ & $\begin{array}{c}\text { TIS } \\
(n=48)\end{array}$ & $\begin{array}{c}\text { Difference } \\
\text { TIP-TIS } \\
\text { LMS* }(85 \% \text { CI) }\end{array}$ & $P$ & $\begin{array}{c}\text { TIP } \\
(n=214)\end{array}$ & $\begin{array}{c}\text { TIS } \\
(n=143)\end{array}$ & $\begin{array}{c}\text { Difference } \\
\text { TIP-TIS } \\
\text { LMS* }(85 \% \text { CI) }\end{array}$ & $P$ \\
\hline Effectiveness & 76.9 & 75.6 & $1.30(-6.42$ to 9.02$)$ & .81 & 79.6 & 70.5 & $9.10(5.36$ to 12.83$)$ & $<.001$ & 72.1 & 62.4 & 9.74 (7.06 to 12.42$)$ & $<.001$ \\
\hline Side effects & 92.8 & 98.7 & $-5.90(-10.7$ to -1.09$)$ & .07 & 93.9 & 95.6 & $-1.68(-4.21$ to 0.85$)$ & .34 & 91.5 & 91.5 & $-0.03(-2.35$ to 2.28$)$ & .98 \\
\hline Convenience & 82.8 & 65.7 & $17.10(8.81$ to 25.38$)$ & .005 & 81.6 & 63.7 & $17.91(13.28$ to 22.55$)$ & $<.001$ & 85.0 & 58.3 & 26.65 (23.92 to 29.37$)$ & $<.001$ \\
\hline $\begin{array}{l}\text { Global } \\
\text { satisfaction }\end{array}$ & 77.7 & 78.0 & $-0.34(-7.48$ to 6.80$)$ & .94 & 82.6 & 78.6 & 4.02 ( -0.19 to 8.23$)$ & .17 & 75.1 & 69.6 & 5.58 (2.52 to 8.64$)$ & .009 \\
\hline $\begin{array}{l}{ }^{*} \text { Least-mean }-\mathrm{sq} \\
\mathrm{TIP}=\text { tobramyc } \\
\mathrm{TIS}=\text { tobramyc }\end{array}$ & $\begin{array}{l}\text { uare (LMS) } \\
\text { in inhalation } \\
\text { in inhalation }\end{array}$ & $\begin{array}{l}\text { values for a } \\
\text { a powder } \\
\text { a solution }\end{array}$ & verages of the 3 treatment & & & & & & & & & \\
\hline
\end{tabular}

Table 5. Most Frequent Adverse Events in All the Treatment Cycles

\begin{tabular}{|c|c|c|c|c|c|c|}
\hline & \multicolumn{6}{|c|}{ Number (percent) } \\
\hline & \multicolumn{2}{|c|}{ Age $\geq 6$ to $<13(n=46)$} & \multicolumn{2}{|c|}{ Age $\geq 13$ to $<20(n=114)$} & \multicolumn{2}{|c|}{ Age $\geq 20(n=357)$} \\
\hline & $\operatorname{TIP}(n=28)$ & TIS $(n=18)$ & $\operatorname{TIP}(n=66)$ & TIS $(n=48)$ & TIP $(n=214)$ & TIS $(n=143)$ \\
\hline Any adverse event, $n(\%)$ & $25(89.3)$ & $15(83.3)$ & $59(89.4)$ & $39(81.3)$ & $194(90.7)$ & $122(85.3)$ \\
\hline Cough & $18(64.3)$ & $4(22.2)$ & $35(53.0)$ & $13(27.1)$ & $96(44.9)$ & $48(33.6)$ \\
\hline Lung disorder* & $5(17.9)$ & $9(50.0)$ & $20(30.3)$ & $11(22.9)$ & $78(36.4)$ & $43(30.1)$ \\
\hline Productive cough & $5(17.9)$ & $3(16.7)$ & $13(19.7)$ & $4(8.3)$ & $38(17.8)$ & $34(23.8)$ \\
\hline Dysphonia & $6(21.4)$ & $1(5.6)$ & $7(10.6)$ & $2(4.2)$ & $29(13.6)$ & $5(3.5)$ \\
\hline Hemoptysis & $0(0)$ & $2(11.1)$ & $9(13.6)$ & $5(10.4)$ & $31(14.5)$ & $19(13.3)$ \\
\hline Oropharyngeal pain & $5(17.9)$ & $1(5.6)$ & $13(19.7)$ & $2(4.2)$ & $25(11.7)$ & $19(13.3)$ \\
\hline Sinusitis & $1(3.6)$ & $1(5.6)$ & $0(0)$ & $5(10.4)$ & $17(7.9)$ & $9(6.3)$ \\
\hline Upper respiratory tract infection & $2(7.1)$ & $4(22.2)$ & $3(4.5)$ & $6(12.5)$ & $16(7.5)$ & $8(5.6)$ \\
\hline Rhinorrhea & $6(21.4)$ & $1(5.6)$ & $6(9.1)$ & $2(4.2)$ & $10(4.7)$ & $12(8.4)$ \\
\hline Decreased appetite & $4(14.3)$ & $(0)$ & $3(4.5)$ & $2(4.2)$ & $6(2.8)$ & $5(3.5)$ \\
\hline Dysgeusia & $3(10.7)$ & $0(0)$ & $4(6.1)$ & $0(0)$ & $5(2.3)$ & $1(0.7)$ \\
\hline Pneumonia & $3(10.7)$ & $0(0)$ & $0(0)$ & $1(2.1)$ & $1(0.5)$ & $2(1.4)$ \\
\hline
\end{tabular}

Events are ordered by decreasing frequency according to the tobramycin inhalation powder (TIP) $\geq 20$ years old (adult) group.

* Lung disorders were generally reported by the investigator as a pulmonary or cystic fibrosis exacerbation. A subject with multiple occurrences of the same adverse event was counted only once in that adverse event category.

TIS $=$ tobramycin inhalation solution

parison of treatment effect within the subgroups for these end points. For example, additional anti-pseudomonal antibiotic use was greater in subjects receiving TIP than in those receiving TIS, although only in adolescents and adults. We suspect that the use of oral antibiotics may have been driven by the higher incidence of cough in the TIP group, which could have been interpreted by clinicians as a symptom of an exacerbation, or led to an increase in self-medication among patients. Despite this higher incidence, the duration of use of antibiotics was shorter in subjects receiving TIP than in those receiving TIS ( 36.5 vs $55 \mathrm{~d}$ and $32.2 \mathrm{vs} 36.4 \mathrm{~d}$ for adolescents and adults, respectively). In addition, there were fewer hospitalizations in children treated with TIP than with TIS, and the mean duration of hospitalization was also shorter. Including all subjects, the mean duration of hospital stay per subject was shorter for TIP than TIS in all 3 age subgroups. It will be interesting to determine whether these trends are borne out in larger clinical studies and/or clinical practice.

Global satisfaction, measured with the Treatment Satisfaction Questionnaire for Medication, was higher in the 2 older subject groups treated with TIP, compared with TIS. All the groups were more satisfied with the effectiveness of TIP than TIS ( $P \leq .001$ for the 2 older groups). The convenience domain was also rated higher by all age groups for TIP, which may reflect the average TIP administration time of $6 \mathrm{~min}$, compared with $20 \mathrm{~min}$ for TIS (excluding the time required for cleaning and sterilizing the equipment). ${ }^{12}$ This is likely to be appreciated by older subjects, who are both more independent and likely to be 


\section{Tobramycin Inhalation Powder in Cystic Fibrosis Patients: Response by Age Group}

receiving more medications than the younger age group. It is also interesting that the adults reported higher satisfaction despite having lower lung-function responses to TIP than the younger age group. This could suggest that subject satisfaction scores reflect a more holistic response to treatment, which objective measures do not capture.

In terms of safety, the frequency of adverse events was comparable between treatments and across all age groups, with the exception of some respiratory symptoms, which were more prevalent in the TIP group, most notably cough and dysphonia. Cough is a common symptom of inhalation therapies ${ }^{16}$ and of $\mathrm{CF}$ disease. The higher rates of cough and dysphonia may be attributable to the high 'payload' of powder in the TIP formulation. ${ }^{16}$ Nevertheless, the severity of most of the adverse events, including cough, was mild to moderate in both treatment arms, ${ }^{12}$ and the impact of the adverse effects on the subjects' lives was comparable between the treatment groups, as reflected by the Treatment Satisfaction Questionnaire for Medication scores. Furthermore, the overall pattern of discontinuation does not appear to be driven by the rate or nature of adverse events, so differences between age groups are unlikely to be related to factors inherent to TIP. Persistence with TIP treatment appeared to be greatest in the youngest subjects, who were likely to have less prior exposure to TIS.

Our results are consistent with previous intervention studies in $\mathrm{CF}$, in which the most robust results have been in younger subjects. In the original TIS phase- 3 trial $^{10}$ the best $\mathrm{FEV}_{1}$ response to tobramycin was in the 13-17-yearold group (compared with younger and older subjects), while the $P$. aeruginosa suppressive effect decreased with advancing age. A larger lung function response was also noted in subjects aged 6-17 years than in adults in a study that compared 2 formulations of tobramycin solution for nebulization (Bramitob and TOBI). ${ }^{24}$

Similarly, in a study investigating $\mathrm{FEV}_{1}$ decline with dornase alfa, a statistically significant improvement occurred in children ages $8-17$ years old, but not in adults, ${ }^{25}$ and a 4 -year trial of high-dose ibuprofen ${ }^{19}$ found that children under 13 years benefitted more than older subjects. In addition, in the AIR CF-1 study, subjects $<18$ years had greater improvements in the CF Questionnaire-Revised respiratory symptom score following 4 weeks of treatment with aztreonam lysine for inhalation versus placebo than adults ( $>20$ points vs 6 points, respectively). ${ }^{20}$ Further, a review of pediatric data from studies conducted as part of the aztreonam for inhalation clinical development program found improvements in lung function among children and adolescents with aztreonam lysine for inhalation to be of a magnitude similar to or greater than that in adults, with the greatest improvements in adolescents. ${ }^{26}$ In contrast, recent study ${ }^{27}$ found that adults had bigger gains in lung function with mannitol. However, that result may have been driven by a positive response to the control treatment (ie, lowdose mannitol) in the younger age groups.

It is not clear why treatment response should be greater in younger subjects. Explanations may include better adherence to therapy and less prior exposure to antibiotics among younger subjects. While any prior exposure to tobramycin did not appear to differ by age in our analysis, the lifetime length of exposure may have been less in children simply because they are younger and had not had $P$. aeruginosa infection for as long, and older subjects with more prolonged exposure to tobramycin may have a diminishing response over time. Younger subjects may also have more capacity to respond to treatment. Continuing lung growth in children, which has been correlated with improvements in maximal expiratory flow and upstream airway conductance, ${ }^{28}$ could facilitate response to treatment in some subjects. In addition, children demonstrate greater 'elasticity' of lung function, which declines over time. ${ }^{29}$

As patients with $\mathrm{CF}$ age and the disease progresses, repeated infections and chronic $P$. aeruginosa infection lead to lung damage and permanent loss of lung function, which may also reduce their capacity to respond to treatment. Interestingly, in our study those with more severe disease seemed to achieve greater improvements in lung function (as measured by the change in percent-of-predicted $\mathrm{FEV}_{1}$ from baseline) after treatment with tobramycin than those with less severe disease (see Table 2). However, in our study the impairment of lung function at baseline was used as a measure of lung damage, since we did not assess the extent of bronchiectactic tissue or other measures of anatomical disease severity. TIP and TIS reduce the burden of $P$. aeruginosa infection, which in younger patients with potentially less lung damage, can lead to a marked improvement in lung function. The less marked impact of TIP or TIS in subjects with less severe impairment of $\mathrm{FEV}_{1}$ may reflect the difficulty in achieving meaningful $\mathrm{FEV}_{1}$ changes in patients with better lung function at baseline. ${ }^{30}$ Clearly, further research is needed. Previous medication use may have an influence, but information on this is limited in the current study.

\section{Limitations}

Our analysis was a post hoc subgroup analysis of a larger randomized trial, and therefore carries the potential for bias inherent in such an analysis. In addition, while the original study was not powered to detect statistical differences between subgroups, we have carried out statistical analyses of the treatment differences by subgroup for percent-of-predicted $\mathrm{FEV}_{1}, P$. aeruginosa sputum density, and treatment satisfaction. Although the subjects were randomized to treatment, randomization was not stratified by age, such that there were some differences between the treat- 


\section{Tobramycin Inhalation Powder in Cystic Fibrosis Patients: Response by Age Group}

ment groups within the age-related subgroups. Statistical comparisons by age subgroups, which in some cases included relatively small numbers of subjects, should be interpreted with caution, because differences between groups may have occurred by chance. These types of analyses are at risk of type- 1 error because of multiple comparisons. The fact that younger subjects treated with TIP had better efficacy outcomes than those treated with TIS may have been at least partially attributable to the less severe disease in children receiving TIP, although the differences were not statistically significant. However, for the whole population in this study, those with more severe disease (ie, percent-of-predicted $\mathrm{FEV}_{1}<50 \%$ ) had better improvements in lung function. The impact of this finding is therefore unclear. The treatments were also open-label, and this may have affected the results, particularly the Treatment Satisfaction Questionnaire for Medication scores. However, we observed consistent trends within each age group, indicating that, overall, TIP was at least as effective as TIS, and these trends are consistent with the overall findings of the EAGER study. ${ }^{12}$

\section{Conclusions}

In summary, TIP was comparable to TIS for all age groups, as measured by mean changes in lung function and $P$. aeruginosa sputum density from baseline. Children treated with TIP tended to have greater (although not statistically significant) improvements in efficacy outcomes than those treated with TIS, confirming that children can use the T-326 inhaler effectively. With the exception of cough and dysphonia, the safety and tolerability profile of TIP was similar to that of TIS across all age groups. Adverse events suggestive of local tolerability, such as cough, are not unexpected, given the dry powder formulation. ${ }^{31}$ Subject satisfaction, as measured by convenience of use, was higher with TIP than with TIS in all age groups.

Relative to nebulized tobramycin treatment, the drugdevice combination of TIP provides a faster, ${ }^{15,16}$ more portable, and convenient treatment option with similar efficacy, and can be used in patients with $\mathrm{CF}$ as young as 6 years.

\section{ACKNOWLEDGMENTS}

We thank Robert Wan and Amitava Mukhopadhyay, Novartis Pharmaceuticals, Basel, Switzerland, for statistical assistance, and Mary Sayers, CircleScience, London, United Kingdom, for editorial assistance. This assistance was funded by Novartis Pharmaceuticals.

\section{REFERENCES}

1. Høiby N, Frederiksen B, Pressler T. Eradication of early Pseudomonas aeruginosa infection. J Cyst Fibros 2005;4(Suppl 2):49-54.

2. Flume PA, O'Sullivan BP, Robinson KA, Goss CH, Mogayzel PJ Jr, Willey-Courand DB, et al; Cystic Fibrosis Foundation; Pulmonary
Therapies Committee. Cystic fibrosis pulmonary guidelines: chronic medications for maintenance of lung health. Am J Respir Crit Care Med 2007;176(10):957-969.

3. Daniels T, Goodacre L, Sutton C, Pollard K, Conway S, Peckham D. Accurate assessment of adherence: self-report and clinician report vs electronic monitoring of nebulizers. Chest 2011;140(2):425-432.

4. Dodd ME, Webb AK. Understanding non-compliance with treatment in adults with cystic fibrosis. J R Soc Med 2000;93(Suppl 38):2-8.

5. Sawicki GS, Sellers DE, Robinson WM. High treatment burden in adults with cystic fibrosis: challenges to disease self-management. J Cyst Fibros 2009;8(2):91-96.

6. Briesacher BA, Quittner AL, Saiman L, Sacco P, Fouayzi H, Quittell LM. Adherence with tobramycin inhaled solution and health care utilization. BMC Pulm Med 2011;11:5. DOI: 10.1186/1471-246611-5.

7. Eakin MN, Bilderback A, Boyle MP, Mogayzel PJ, Riekert KA. Longitudinal association between medication adherence and lung health in people with cystic fibrosis. J Cyst Fibros 2011;10(4):258264.

8. Sawicki GS, Signorovitch JE, Zhang J, Latremouille-Viau D, von Wartburg M, Wu EQ, Shi L. Reduced mortality in cystic fibrosis patients treated with tobramycin inhalation solution. Pediatr Pulmonol 2012;47(1):44-52.

9. Murphy TD, Anbar RD, Lester LA, Nasr SZ, Nickerson B, VanDevanter DR, Colin AA. Treatment with tobramycin solution for inhalation reduces hospitalizations in young $\mathrm{CF}$ subjects with mild lung disease. Pediatr Pulmonol 2004;38(4):314-320.

10. Ramsey BW, Pepe MS, Quan JM, Otto KL, Montgomery AB, Williams-Warren J, et al; Cystic Fibrosis Inhaled Tobramycin Study Group. Intermittent administration of inhaled tobramycin in patients with cystic fibrosis. N Engl J Med 1999;340(1):23-30.

11. vanDyke R, McPhail GL, Kahill L, Fenchel M, Carle A, Amin R, et al. Effects of long-term tobramycin on lung function decline in children with cystic fibrosis (abstract \#328). Pediatr Pulmonol 2011; 46(Suppl 34):330.

12. Konstan MW, Flume PA, Kappler M, Chiron R, Higgins M, Brockhaus F, et al. Safety, efficacy and convenience of tobramycin inhalation powder in cystic fibrosis patients: the EAGER trial. J Cyst Fibros 2011;10(1):54-61.

13. Harrison MJ, McCarthy M, Fleming C, Hickey C, Shortt C, Eustace JA, et al. Improved adherence, tolerability and low discontinuation rate in a prospective real world study with tobramycin inhaled powder (TIP) compared to tobramycin inhaled solution (TIS) in cystic fibrosis (CF). Irish J Med Sci 2012;181(Suppl 10):S403.

14. Geller DE, Weers J, Heuerding S. Development of an inhaled drypowder formulation of tobramycin using PulmoSphere technology. J Aerosol Med Pulm Drug Deliv 2011;24(4):175-182.

15. Newhouse MT, Hirst PH, Duddu SP, Walter YH, Tarara TE, Clark $\mathrm{AR}$, et al. Inhalation of a dry powder tobramycin PulmoSphere formulation in healthy volunteers. Chest 2003;124(1):360-366.

16. Geller DE, Konstan MW, Smith J, Noonberg SB, Conrad C. Novel tobramycin inhalation powder in cystic fibrosis subjects: pharmacokinetics and safety. Pediatr Pulmonol 2007;42(4):307-313.

17. Geller DE. Comparing clinical features of the nebulizer, metereddose inhaler, and dry powder inhaler. Respir Care 2005;50(10):13131321.

18. Virchow JC, Crompton GK, Dal Negro R, Pedersen S, Magnan A, Seidenberg $\mathrm{J}$, et al. Importance of inhaler devices in the management of airway disease. Respir Med 2008;102(1):10-19.

19. Konstan MW, Byard PJ, Hoppel CL, Davis PB. Effect of high-dose ibuprofen in patients with cystic fibrosis. N Engl J Med 1995;332(13): 848-854.

20. Retsch-Bogart GZ, Quittner AL, Gibson RL, Oermann CM, McCoy KS, Montgomery AB, et al. Efficacy and safety of inhaled aztreonam 


\section{Tobramycin Inhalation Powder in Cystic Fibrosis Patients: Response by Age Group}

lysine for airway pseudomonas in cystic fibrosis. Chest 2009;135(5): 1223-1232.

21. Knudson RJ, Lebowitz MD, Holberg CJ, Burrows B. Changes in the normal maximal expiratory flow-volume curve with growth and aging. Am Rev Respir Dis 1983;127(6):725-734.

22. Atkinson MJ, Sinha A, Hass SL, Colman SS, Kumar RN, Brod M, et al. Validation of a general measure of treatment satisfaction, the Treatment Satisfaction Questionnaire for Medication (TSQM), using a national panel study of chronic disease. Health Qual Life Outcomes 2004;2:12. DOI: 10.1186/1477-7525-2-36.

23. Tiddens HA, Geller DE, Challoner P, Speirs RJ, Kesser KC, Overbeek SE, et al. Effect of dry powder inhaler resistance on the inspiratory flow rates and volumes of cystic fibrosis patients of six years and older. J Aerosol Med 2006;19(4):456-465.

24. Mazurek H, Lenoir G, Pelikan L, Geidel C, Bolbas K, Antipkin Y, et al. Head-to-head comparison of two inhaled tobramycin solutions in cystic fibrosis (CF) patients with chronic Pseudomonas aeruginosa (Pa) infection. J Cyst Fibros 2011;10(Suppl 1):28S.

25. Konstan MW, Wagener JS, Pasta DJ, Millar SJ, Jacobs JR, Yegin A, et al; Scientific Advisory Group and Investigators and Coordinators of Epidemiologic Study of Cystic Fibrosis. Clinical use of dornase alpha is associated with a slower rate of $\mathrm{FEV}_{1}$ decline in cystic fibrosis. Pediatr Pulmonol 2011;46(6):545-553.

26. Retsch-Bogart GZ, McKoy KS, Oermann CM, Lewis S, Bresnik M, Assael BM. Aztreonam for inhalation solution (AZLI) clinical development program: combined pediatric experience (abstract \#305). Pediatr Pulmonol 2011;46(Suppl 34):322.

27. Aitken ML, Flume PA, Geller DE, Lapey A, Zuckerman J, De Boeck, $\mathrm{K}$, et al. Efficacy and safety by age group from the Phase III studies of bronchitol (inhaled mannitol) in patients with CF. Pediatr Pulmonol 2011;46(Suppl 34):P236.

28. Zapletal A, Houstek J, Samanek M, Vavrova V, Srajer J. Lung function abnormalities in cystic fibrosis and changes during growth. Bull Eur Physiopathol Respir 1979;15(4):575-592.

29. Hart N, Polkey MI, Clément A, Boulé M, Moxham J, Lofaso F, et al. Changes in pulmonary mechanics with increasing disease severity in children and young adults with cystic fibrosis. Am J Respir Crit Care Med 2002;166(1):61-66.

30. Ballmann M, Smyth A, Geller DE. Therapeutic approaches to chronic cystic fibrosis respiratory infections with available, emerging aerosolized antibiotics. Respir Med 2011;105(Suppl 2):S2-S8.

31. Hurt K, Bilton D. Inhaled mannitol for the treatment of cystic fibrosis. Expert Rev Respir Med 2012;6(1):19-26. 